\title{
Logistics service provider selection for disaster preparation: a socio-technical systems perspective
}

\author{
Seongtae $\mathrm{Kim}^{1} \cdot$ M. Ramkumar ${ }^{1}$ - Nachiappan Subramanian ${ }^{2}$ \\ Published online: 24 December 2018 \\ (c) The Author(s) 2018
}

\begin{abstract}
Since 1990s, the world has seen a lot of advances in providing humanitarian aid through sophisticated logistics operations. The current consensus seems to be that humanitarian relief organizations (HROs) can improve their relief operations by collaborating with logistics service providers (CLSPs) in the commercial sector. The question remains: how can HROs select the most appropriate CLSP for disaster preparation? Despite its practical significance, no explicit effort has been done to identify the criteria/factors in prioritizing and selecting a CLSP for disaster relief. The present study aims to address this gap by consolidating the list of criteria from a socio-technical systems (STS) perspective. Then, to handle the interdependence among the criteria derived from the STS, we develop a hybrid multi-criteria decision making model for CLSP selection in the disaster preparedness stage. The proposed model is then evaluated by a real-life case study, providing insights into the decision-makers in both HROs and CLSPs.
\end{abstract}

Keywords Logistics service provider - Disaster relief operations · Socio-technical systems · Multi-criteria decision analysis $\cdot$ Service provider selection

\section{Introduction}

Since 1990s, the number of disasters have grown up, affecting millions of people (roughly 200-300) annually and causing serious damages to the world economy, e.g., $0.09 \%$ of the

Seongtae Kim

seokim@ethz.ch

M. Ramkumar

ramkumar@ethz.ch

Nachiappan Subramanian

n.subramanian@sussex.ac.uk

1 Department of Management, Technology, and Economics, Swiss Federal Institute of Technology Zurich, Weinbergstrasse 56/58, 8092 Zurich, Switzerland

2 School of Business, Management and Economics, University of Sussex, Jubilee Building 302, Brighton BN1 9SL, UK 
2015 world GDP (Guha-Sapir et al. 2015). Among the disasters of all time, the 2004 Asian Tsunami has stimulated waves among the public in recognizing logistics as a vital feature of disaster relief operations (Kovács and Spens 2007, 2009). Since then, the world has seen a lot of advances in providing humanitarian aid through logistics operations that account for the majority of disaster relief. The role of commercial logistics service provider (hereafter "CLSP") in disaster relief has now gained much attention from practitioners, as well as from the academic community (Vega and Roussat 2015).

CLSPs participate in humanitarian operations as a philanthropic or commercial purpose. On one hand, CLSPs have provided contributions to humanitarian appeals by undertaking hands-on activities such as voluntary partnerships with humanitarian relief organizations (HROs). Doing so would create value for the CLSPs, as such a philanthropic effort helps to satisfy the needs of stakeholders (Kim and Lee 2012), and thus to improve their public image (Bealt et al. 2016). On the other hand, CLSPs' activities are also "outsourced" (Wang et al. 2016) by those HROs who provide relief service but do not have sufficient resources (e.g., transportation fleets) for recovery (Balcik and Beamon 2008; Baharmand et al. 2017). In this sense, HROs act as "customers" (Vega and Roussat 2015), and can improve their relief operations by working with CLSPs. The question remains: how can HROs select the most appropriate CLSP for disaster preparation?

It is a major challenge for HROs to select the best CLSP during the preparedness stage. The challenge has to do with the following issues: first, what are the criteria involved in the selection of CLSP?; and second, how can such criteria be prioritized for the appropriate CLSP in disaster relief? Despite its practical significance, no explicit effort has been done to identify factors in selecting a right CLSP for disaster relief. This lack of research is surprising given that the CLSP selection approach originally developed for commercial activities can be applicable in the context of humanitarian operations (Holguín-Veras et al. 2012; Swansson and Smith 2013). In this study, we aim to rectify this gap by consolidating the list of criteria from a socio-technical systems (STS) perspective, a theoretical view that is closely associated with humanitarian logistics (Holguín-Veras et al. 2012).

In recent years, multi-criteria decision making (MCDM) methods have been used for disaster relief operations (e.g., Sharma et al. 2017; Trivedi and Singh 2017). The main goal of this MCDM method is to help decision makers to arrive at consensus based on value judgements, group decision making principles, rather than on individual opinions that often lead to bias in decision making (Ramkumar et al. 2016). Some researchers (e.g., Abidi et al. 2015; Kabra and Ramesh 2015) have applied Analytic Hierarchical Process (AHP) based MCDM method to selection-related humanitarian issues, and assumed the used criteria to be independent. In the real world, however, the selection criteria are seldom independent, but always have some sort of interrelationships among themselves with cause and effect relationships (Ramkumar et al. 2016; Sharma et al. 2017).

Given the context, this study focuses on an assessment framework that combines two MCDM techniques: Decision Making Trial and Evaluation Laboratory (DEMATEL) based Analytic Network Process (ANP) (hereafter "DANP") and Complex Proportional Assessment of Alternatives to Grey Relations (COPRAS-G) technique. Unlike AHP or ANP, this hybrid MCDM approach has several benefits. First, it takes the interdependence of STS criteria into account while calculating the global weights. Second, the global weights act as an input along with expert opinion for calculating desirability index of candidate CLSPs. Third, the network relationship map (NRM) derived from DANP demonstrates the inter-relationship among the criteria. Finally, the COPRAS-G based desirability index gives a quantitative measure for final CLSP selection. To the best of our knowledge, this is the first study to apply DANP and COPRAS-G into the selection of CLSP within the humanitarian logistics context, where 
"a wider variety of analytic approaches would benefit the community" (Griffith et al. 2017, p. 4).

This paper enriches the field of research by making the following contributions. First, this study takes a first step to identify a unique set of criteria for CLSP selection in preparation for disaster relief. This was done by analyzing literature based on STS theory, and then by having a discussion with the executives of a HRO. Secondly, this study identifies the interdependency among the dimensions/criteria, and then suggests a DANP and COPRAS-G based assessment framework. While DANP was used to calculate weights for independent criteria, COPRAS-G was applied to rank and select the most suitable CLSP. The proposed model was then evaluated by a real-life case study. Finally, this study recognizes the requirement of diversified expertise both on technical and domain knowledge for making a right decision, proposing to use in group decision making.

The rest of this study proceeds as follows. In the next section, we present a brief background on humanitarian logistics literature, with a particular focus on the role of CLSP and its selection issues for disaster relief, and on the STS view employed in this study. Then, we provide the proposed DANP model and COPRAS-G based approaches, followed by its application to a case study in India. We close with a discussion of our results, implications for research and practice, followed by conclusion with study limitations.

\section{Background}

As shown in Fig. 1, the Web of Science search using the "humanitarian logistics" keyword revealed 406 relevant articles from more than 100 multi-disciplinary journals. This is comparable to using the broader keyword "humanitarian operations," especially in recent years. This trend is clearly in line with the below argument that logistics plays a major role in disaster relief. Figure 1 also reveals the rapid growth in research on this field over the last decade (from 2008). Despite the growing interest, yet, no research we are aware of provides a framework for CLSP selection in the disaster preparedness stage. This lack of research is

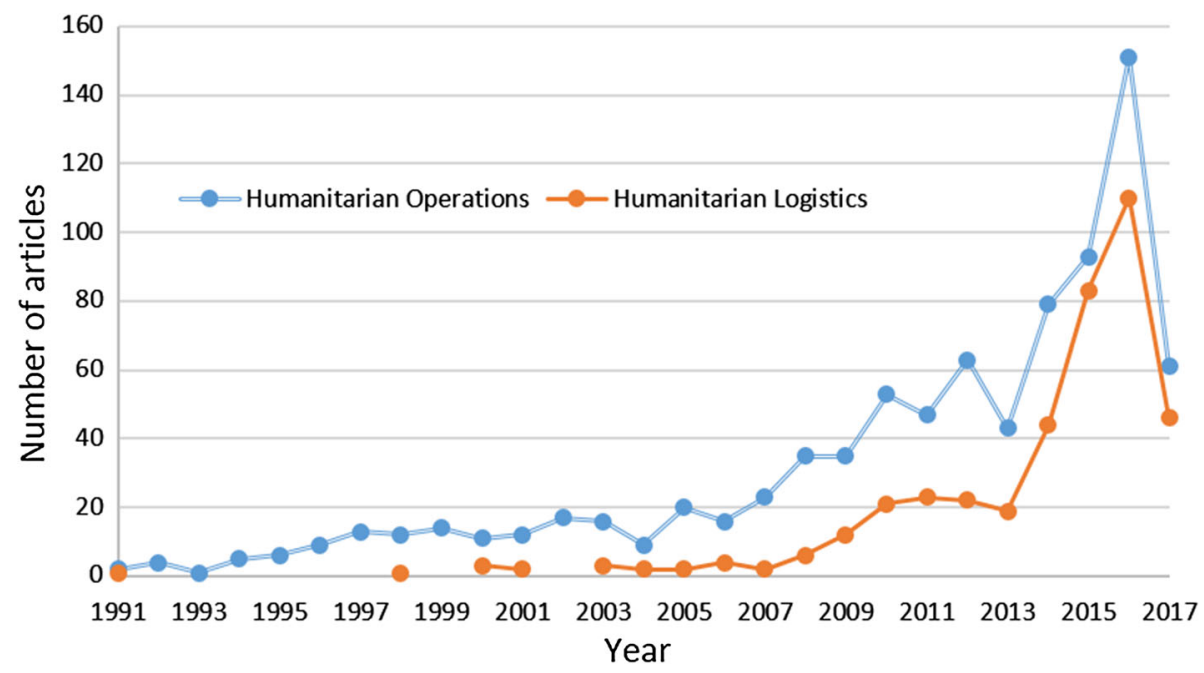

Fig. 1 Number of articles published from 1991 to August 2017 
troubling given that "delivery of adequate relief supplies from local and/or international suppliers are typically time-consuming and expensive", and therefore that "[HROs] engage in preparatory activities that enhance their logistics capabilities in responding to emergencies" (Balcik and Beamon 2008, p. 102).

\subsection{The role of CLSP in disaster relief}

The role of logistics is crucial for disaster relief operations (Cozzolino et al. 2017). However, in this field of research, the use of the term, logistics, seems limited to the activities led by HROs. For example, Rodríguez-Espíndola et al. (2018) highlight the importance of logistics in disaster relief operations. While this study provides an excellent overview, their discourse on such a matter is primarily focused on the logistics activities of HROs. In contrast, much less is known about the role of commercial service providers like CLSP in disaster relief. Indeed, as noted by Vega and Roussat (2015, p. 353), "the role of [C]LSPs in humanitarian relief is seldom discussed in the academic literature." This is surprising given that the importance of CLSP in humanitarian operations has been highlighted over the last decade (Van Wassenhove 2006; Kovács and Spens 2007; Maon et al. 2009; Swansson and Smith 2013; Bealt et al. 2016).

However, in recent years, few attempts have been made to rectify this gap. Vega and Roussat's (2015) study is one of the initial efforts. By using a two-stage exploratory approach, they found that CLSPs play an important part in humanitarian relief operations. In particular, their analysis suggests that CLSPs present three different emerging roles in humanitarian relief, as briefly outlined next. Firstly, as "members", CLSPs participate in disaster relief for the sake of demonstrating corporate social responsibility (CSR) by sharing their resources with HROs. Next, as "tools", CLSPs are likely to act as operators, providing the required service on a contract basis. Finally, as "actors", CLSPs support HROs through partnerships. In this role, CLSPs provide more advanced logistics services, thereby coordinating the relief operations on behalf of a customer (i.e., HROs).

While Vega and Roussat (2015) provide an overview of the CLSP role in the context of disaster relief operations, more recent two studies extend it by exploring the benefits of using commercial service provider. One is by Cozzolino et al. (2017), which investigated CLSPs' engagement in disaster relief initiatives. Based on multiple case studies, the authors found that these relief initiatives are likely to deliver knowledge, expertise and goods to HROs, contributing to relief operations. Another study is by Baharmand et al. (2017), which delved into the impact of using CLSP in disaster relief from the 2015 Nepal earthquake case. Their field research suggests that the use of CLSP minimizes the probability of transportation risks occurring in HRO such as delivery delays, insufficient capacity, and market fluctuations. Indeed, CLSPs can bring "solutions for several challenges and issues of" HROs (Baharmand et al. 2017, p. 556).

It should be noted that the discourse of the role of CLSPs in times of disaster is in line with the discourse of what is called "public-private partnerships" (PPPs). PPPs are based on a premise that "as disaster become increasingly complex, better collaboration not only with governments, the military, other humanitarian organizations, but also through partnerships with private business becomes ever more important" (Van Wassenhove 2006, p. 487). A number of studies have highlighted the contribution of private sectors (Kovács and Spens 2007; Stewart et al. 2009; Gabler et al. 2017) in disaster relief operations, especially that of CLSPs (Tomasini and Van Wassenhove 2009; Swansson and Smith 2013; Bealt et al. 2016). For example, when Hurricane Katrina hit, the US public agency struggled with the immediate disaster response mainly due to the antiquated logistics systems, poor planning, and lack of 
personnel (Swansson and Smith 2013). In contrast, Wal-Mart and other private companies played an efficient and effective role in the disaster relief process, saving more lives (Horwitz 2008; Wang et al. 2016).

It should be also noted that "when disaster strikes and the needs peak, it is already too late to develop solutions that were not in place before" (Tomasini and Van Wassenhove 2009, p. 554). Thus, the solutions must be established before a disaster strikes. That is, the success of disaster response depends on how well HROs develop the solutions in the preparedness stage (Rodríguez-Espíndola et al. 2018). For example, before the 2011 Gujarat earthquake, some HROs had performed disaster preparedness initiatives, like placing logistics at the heart of operations, and this helped them to respond to the disaster more effectively (for details, see Van Wassenhove, 2006). Indeed, the better prepared HROs are for disaster relief, the more likely they will provide a successful response. More importantly, "the key to being better prepared is that logistics has to be recognized and understood as an intrinsic element" (Van Wassenhove 2006, p. 481).

\subsection{CLSP selection for disaster relief}

As discussed earlier, for the times of humanitarian crisis, the need for activities by CLSP is increasing rapidly because of its ability to remedy the magnitude of the catastrophic events. The basic task of CLSP undergoing humanitarian relief operations comprises acquiring and delivering requested supplies at the places and times they are needed (Van Wassenhove 2006). In the aftermath of any disaster, these requested supplies often include items that are vital for survival, such as food, water, temporary shelter and medicine, among others (Balcik and Ak 2014; Griffith et al. 2017). Many HROs are now coming up with the idea of expanding their work and of working with CLSPs. However, research towards the selection of an appropriate CLSP is still lacking.

Selection issues in the field of humanitarian relief can be observed, but from a different angle. For example, Balcik and Ak (2014) consider selection decisions for relief procurement. In particular, the authors address a supplier selection problem for establishing long-term agreements, an approach that ensures quick and cost-effective procurement of relief supplies in responding to sudden disasters. Using the criteria commonly applied for commercial procurement (e.g., quality and price), they develop a stochastic programming model that is then demonstrated through a case study, providing HROs with insights for better assessing candidate suppliers (also cf. Balcik and Beamon 2008). While selecting suppliers for relief supplies, humanitarian logisticians also face challenges where to locate distribution centers (DCs) and temporary shelter sites. In this regard, some scholarly efforts have been made to tackle the challenges. Burkart et al.'s (2017) study is such an effort, introducing an optimal location of DCs for food aid with consideration for beneficiary behavior. K1lc1 et al. (2015) is another example, which develops a mathematical model for the problem of selecting the best shelter site locations.

To the best of our knowledge, however, there is no study that addresses CLSP selection in preparation for disaster relief. This gap is more pronounced when compared to a vast amount of research in the commercial field (e.g. Jharkharia and Shankar 2007), also when considering that CLSPs do account for the majority of the disaster relief process (Vega and Roussat 2015). As noted earlier, we found that there are extant studies that discuss the role/impact of CLSP in humanitarian relief operations (Vega and Roussat 2015; Bealt et al. 2016; Baharmand et al. 2017; Cozzolino et al. 2017). While they provide an excellent discussion on that matter, these 
studies still fail to address CLSP selection issues for HROs, which we aim to overcome in the present study.

\subsection{STS view on humanitarian logistics}

The basic assumption of STS theory is that every organization is "made up of people (the social system) using tools, techniques, and knowledge (the technical system) to produce goods or services valued by customers (who are part of the organization's external environment)" (Pasmore 1988, p. 1). This concept originally comes from the field of British coal mining studies. It is now being applied by many scholars to better understand organizational outcomes such as performance, quality of work life, and to name a few (Griffith and Dougherty 2001). Logistics and supply chain scholars are no exception. Many have used aspects of STS theory, in terms of exploring topics like product complexity (Closs et al. 2008), lean service (Hadid et al. 2016), and supplier integration (Kull et al. 2013). To our knowledge, research has yet to provide a CLSP selection model for disaster preparation from the STS point of view.

In general, STSs have its three underlying sub-systems: environmental, technical and social (Pasmore 1988; Griffith and Dougherty 2001; Kull et al. 2013). The environmental system is associated with environment-related factors such as economic, industrial and governmental contexts. The technical system is comprised of technology-related components such as knowledge and techniques. Finally, the social system consists of human-related factors such as relations, culture and norms. These three sub-systems of STSs are known to interact with each other, thereby providing insights into the understanding of the relationships between people, technology and organizational outcomes. Indeed, as noted by Pasmore (1988, p. 155), "whenever there are people, working together in a system with technology, in an environment that provides resources the system needs, there is the possibility of adapting STS thinking."

Logistics operations for humanitarian relief can also be seen from a STS perspective, as it is all about the process whereby "a social network of individuals (e.g., carriers, drivers, receivers, warehouse operators) arranges a series of technical tasks (e.g., inventory management, routing, pricing) that depend on the supporting systems available at that particular location (e.g., transportation systems, communication technologies)" (Holguín-Veras et al. 2012, p. 498). In this study, we view that HROs adopt STS thinking and thus use aspects of this theory within a humanitarian context. Building on this, this study seeks to explain what factors are crucial for an HRO when it comes to collaborating with a CLSP, and how the HRO can select the best CLSP in preparation for disaster relief. To do this, this study first identifies key selection factors for disaster relief operations, which we outline in the next section.

\section{Model}

This study positions CLSP selection for humanitarian relief as a MCDM problem. The most commonly used approach, i.e., AHP, does not take interdependencies into consideration (Subramanian and Ramanathan 2012). This will be overcome with the adoption of DANP method in this study which offers a rapid robust solution. The process is briefly illustrated in Fig. 2, while the hierarchy for the selection of CLSP is shown in Fig. 3. This study proposes a novel, two-step method for CLSP selection for disaster relief. 


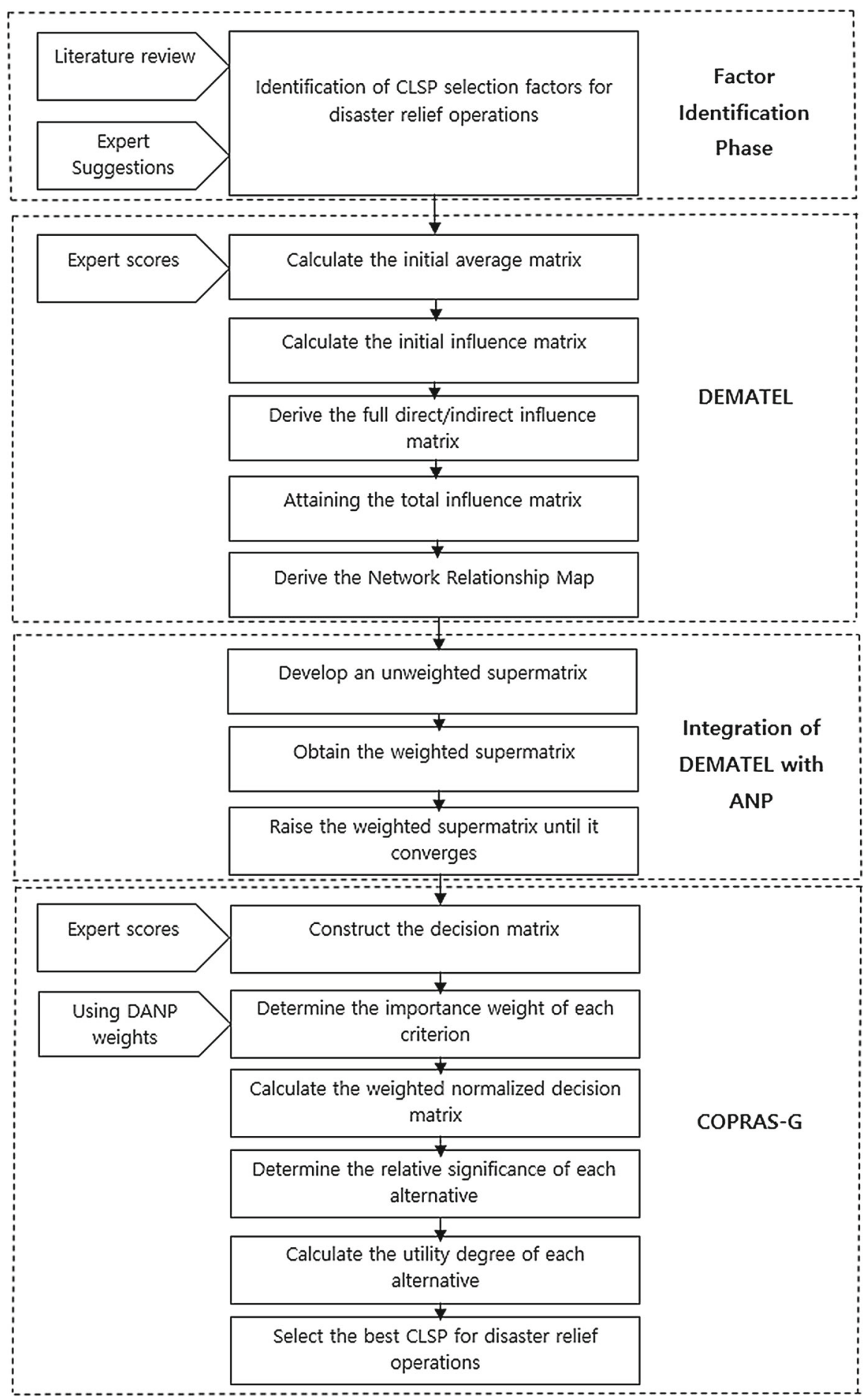

Fig. 2 Framework for the selection of CLSP in the disaster preparedness stage 


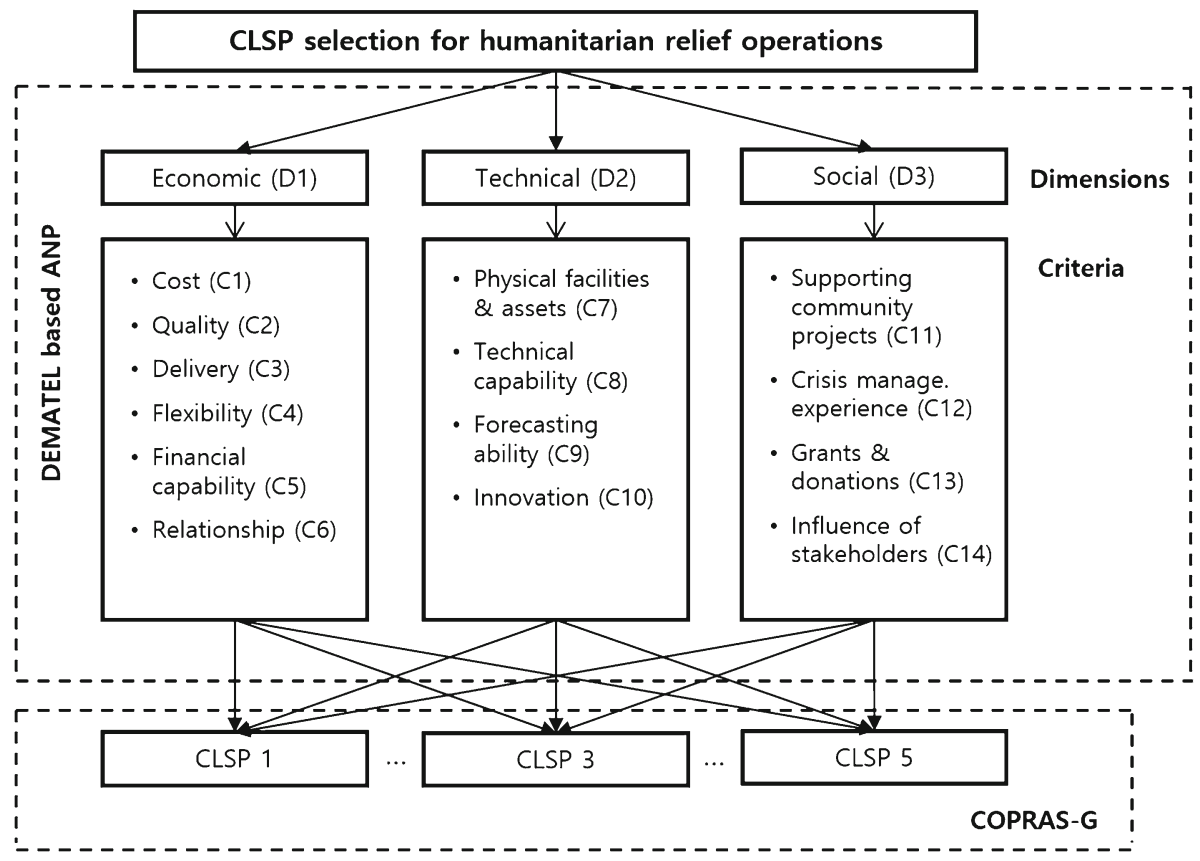

Fig. 3 Hierarchy of CLSP selection model based on a STS perspective

\subsection{Identification of selection factors}

Following prior studies (e.g., Ramkumar et al. 2016), this study selected criteria using a two-step approach: literature survey and expert suggestions. Initially, all possible criteria that could be relevant in CLSP selection for humanitarian relief operations were identified from the literature. This was then combined with expert suggestions for conducting a hybrid DANP-COPRAS-G study on CLSP selection. As a result, as summarized in Table 1, this study selected 14 criteria that can be grouped into three predefined dimensions to build the proposed hybrid MCDM model.

The selected factors are theoretically substantiated by the STS. As shown in Table 1 and Fig. 3, our 14 factors are categorized based on the three sub-systems of the STS: economic, technical and social. Note that this study includes the economic dimension as a representative of environmental system, given that CLSPs are considered for selection in preparation for disaster relief operations. Swansson and Smith (2013) argue that "concepts that originated in commercial logistics as a means for improving customer service levels can be easily adapted to improve response." Also, the economic factor is actually a major part of the environmental system within the STS perspective (Pasmore 1988), supporting our framework. For the purpose of this study, we initially assumed that the criteria and its dimensions for each are interdependent of one another; however, we will show whether and/or how each factor of the STS is interrelated.

Finally, for disaster relief preparedness, the HROs should have a secondary data analysis of CLSPs in their country. In this study, we have thus made a thorough website analysis of top ten logistics companies in India. ${ }^{1}$ As a result, we found that five CLSPs mention their

\footnotetext{
1 https://www.fundoodata.com/learning-center/list-top-10-logistic-companies-india/.
} 
Table 1 Dimensions and criteria for CLSP selection in humanitarian relief

\begin{tabular}{|c|c|c|c|}
\hline Dimensions & Criteria & $\begin{array}{l}\text { Relevance in CLSP selection for } \\
\text { humanitarian relief operations }\end{array}$ & Reference \\
\hline \multirow[t]{6}{*}{ Economic factors (D1) } & Cost (C1) & $\begin{array}{l}\text { The total cost incurred in CLSP } \\
\text { outsourcing for humanitarian relief } \\
\text { operations, which should be } \\
\text { minimum }\end{array}$ & $\begin{array}{l}\text { Jharkharia and } \\
\text { Shankar } \\
\text { (2007) and } \\
\text { Alkhatib } \\
\text { et al. (2015) }\end{array}$ \\
\hline & Quality (C2) & $\begin{array}{l}\text { High quality services like } \\
\text { transportation management that } \\
\text { CLSPs provide during } \\
\text { humanitarian relief operations on a } \\
\text { not-for-profit basis }\end{array}$ & $\begin{array}{l}\text { Vega and } \\
\text { Roussat } \\
(2015)\end{array}$ \\
\hline & Delivery (C3) & $\begin{array}{l}\text { Delivery performance, namely } \\
\text { "speed of operations" and } \\
\text { "reliability", which are important } \\
\text { during disaster relief operations }\end{array}$ & $\begin{array}{l}\text { Jharkharia and } \\
\text { Shankar } \\
\text { (2007) }\end{array}$ \\
\hline & Flexibility (C4) & $\begin{array}{l}\text { Flexibility in adapting to situations } \\
\text { during the relief operations, which } \\
\text { increases goodwill between the } \\
\text { CLSP and the HRO. }\end{array}$ & $\begin{array}{l}\text { Jahre et al. } \\
\text { (2009) }\end{array}$ \\
\hline & $\begin{array}{l}\text { Financial } \\
\text { capability (C5) }\end{array}$ & $\begin{array}{l}\text { A sound financial performance of the } \\
\text { CLSP, which ensures more funds } \\
\text { for projects related to CSR }\end{array}$ & $\begin{array}{l}\text { Vega and } \\
\text { Roussat } \\
(2015)\end{array}$ \\
\hline & Relationship (C6) & $\begin{array}{l}\text { Long-term relationship that includes } \\
\text { shared risks and rewards, thereby } \\
\text { ensuring cooperation between the } \\
\text { CLSP and the HRO. }\end{array}$ & $\begin{array}{l}\text { Jharkharia and } \\
\text { Shankar } \\
\text { (2007) }\end{array}$ \\
\hline \multirow[t]{4}{*}{ Technical factors (D2) } & $\begin{array}{l}\text { Physical facilities } \\
\text { and assets (C7) }\end{array}$ & $\begin{array}{l}\text { Infrastructure of the CLSP in } \\
\text { providing humanitarian relief } \\
\text { activities }\end{array}$ & $\begin{array}{l}\text { Alkhatib et al. } \\
\text { (2015) }\end{array}$ \\
\hline & $\begin{array}{l}\text { Technology } \\
\text { capability (C8) }\end{array}$ & $\begin{array}{l}\text { The capability of the CLSP to } \\
\text { provide services for disaster relief }\end{array}$ & $\begin{array}{l}\text { Kovács et al. } \\
\text { (2012) }\end{array}$ \\
\hline & $\begin{array}{l}\text { Forecasting ability } \\
\text { (C9) }\end{array}$ & $\begin{array}{l}\text { The ability of the CLSP to forecast } \\
\text { various risks in relief operations }\end{array}$ & $\begin{array}{l}\text { Kovács et al. } \\
\text { (2012) }\end{array}$ \\
\hline & Innovation (C10) & $\begin{array}{l}\text { The potentialities of CLSPs to apply } \\
\text { up-to-date innovations, reducing } \\
\text { task duplication and overall } \\
\text { expenditure }\end{array}$ & $\begin{array}{l}\text { Vega and } \\
\text { Roussat } \\
(2015)\end{array}$ \\
\hline \multirow[t]{4}{*}{ Social factors (D3) } & $\begin{array}{l}\text { Supporting } \\
\text { community } \\
\text { projects (C11) }\end{array}$ & $\begin{array}{l}\text { Prior experience of the CLSP in } \\
\text { providing community related } \\
\text { projects }\end{array}$ & $\begin{array}{l}\text { Bai and Sarkis } \\
\text { (2010) }\end{array}$ \\
\hline & $\begin{array}{l}\text { Crisis } \\
\text { management } \\
\text { experience } \\
(\mathrm{C} 12)\end{array}$ & $\begin{array}{l}\text { Prior experience of the CLSP in } \\
\text { providing services for disaster } \\
\text { relief operations }\end{array}$ & $\begin{array}{l}\text { Kovács and } \\
\text { Spens } \\
(2007)\end{array}$ \\
\hline & $\begin{array}{l}\text { Grants and } \\
\text { donations (C13) }\end{array}$ & $\begin{array}{l}\text { The experience of CLSP in raising } \\
\text { grants and donations for supporting } \\
\text { community projects }\end{array}$ & $\begin{array}{l}\text { Bai and Sarkis } \\
\text { (2010) }\end{array}$ \\
\hline & $\begin{array}{l}\text { Influence of } \\
\text { stakeholders } \\
\text { (C14) }\end{array}$ & $\begin{array}{l}\text { The support received by CLSP from } \\
\text { the stakeholders in humanitarian } \\
\text { related activities }\end{array}$ & $\begin{array}{l}\text { Bai and Sarkis } \\
\text { (2010) }\end{array}$ \\
\hline
\end{tabular}


humanitarian activities directly on their websites, while the others only include this activity in additional documents, or do not mention any of these relief activities. Hence this study has initially shortlisted those five CLSPs that have mentioned their humanitarian relief activities directly on their websites. These shortlisted CLSPs will be compared in a later step during the final DANP-COPRAS-G based selection.

\subsection{The DEMATEL technique}

The DEMATEL technique has been widely used in many of the logistics and supply chain management topics, such as city logistics (Tadić et al. 2014), manufacturing (Tzeng and Huang 2014), and supplier selection (Keskin 2015). DEMATEL can confirm interdependence among the criteria and restrict the relationships that reflect characteristics within an essential systematic and developmental trend. The method can be summarized in the following four steps (Ramkumar and Jenamani 2015).

Step 1 Calculate the initial average matrix by scores. The first step is to construct the average matrix $A=\left[a_{i j}\right]_{n \times n}$, where each element is the average score of expert opinions indicating the direct influence of factor $i$ on factor $j$. Each expert gives these ratings using a five point integer scale ranging from 0 indicating "no influence" to 4 indicating "extreme influence."

Step 2 Calculate the initial influence matrix. The initial influence matrix $X=\left[x_{i j}\right]_{n \times n}$ is obtained by normalizing the average matrix $A$, in which all principal diagonal elements equal to zero. Based on $X$, the initial effect that an element receives from another is shown. The map portrays a contextual relationship among the elements of a system to represent the strength of each influence, i.e., affected degree.

Step 3 Derive the full direct/indirect influence matrix. A continuous decrease of the indirect effects of problems can be determined along the powers of $X$, e.g., $X^{2}, X^{3}, \ldots, X^{\mathrm{h}}$ and $\lim _{\mathrm{h} \rightarrow \infty} X^{\mathrm{h}}=[0]_{n \times n}$, where $X=\left[x_{i j}\right]_{n \times n}, 0 \leq x_{i j}<1$ and $0 \leq \sum_{i} x_{i j} \leq 1$ or $0 \leq \sum_{j} x_{i j} \leq 1$ and at least one column or one row of summation, but not all, equals one. If the $(i, j)$ element of the matrix $A$ is denoted by $a_{i j}$, the matrix $X$ can be calculated through the first and second steps, in which all principal diagonal elements are equal to zero.

Step 4 Attain the total-influence matrix T. The total influence matrix can be obtained using the following equation, in which $I$ denotes the identity matrix. $\mathrm{T}=X+X^{2}+X^{3}+\ldots+X^{\mathrm{h}}$ $=X(I-X)^{-1}$ when $\lim _{\mathrm{h} \rightarrow \infty} X^{\mathrm{h}}=[0]_{n \times n}$.

\subsection{Combining DEMATEL with ANP: DANP}

ANP is a MCDM technique that is successfully used in many applications (e.g., Jharkharia and Shankar 2007; Chemweno et al. 2015). The initial step of this technique is the formation of an unweighted super matrix by a pairwise comparisons of the criteria. Subsequently, the weighted supermatrix is derived by dividing each element in a column by the number of clusters, and thus each column will sum to unity.

However, the weighted supermatrix derived by normalizing the unweighted one appears irrational because there are different degrees of influence among the criteria. Hence, many attempts have been made to use the DEMATEL technique to determine the degrees of influence of these criteria and also to normalize the unweighted supermatrix in the ANP. This 
combined approach is called DANP, conducted by the following three steps (Ramkumar and Jenamani 2015).

Step 1 Develop an unweighted super-matrix. The total influence matrix $T_{c}=\left[t_{i j}\right]_{n \times n}$ is obtained by the criteria, and another matrix $T_{D}=\left[t_{i j}^{D}\right]_{m \times m}$ is obtained by the dimensions (clusters) from $T_{c}$. It is then required to normalize the supermatrix $T_{c}$ for the ANP weights of dimensions by using the influence matrix $T_{D}$.

Step 2 Obtain the weighted supermatrix. To this end, each column will sum for normalization. By normalizing the total-influence matrix $T_{D}$, we obtain a new matrix $T_{D}^{\alpha}$.

Step 3 Raise the weighted supermatrix to a sufficiently large power $k$. It is raised until it converges and becomes stable to obtain the global priority vectors, called DANP influential weights, with $\lim _{g \rightarrow \infty}\left(W^{\alpha}\right)^{g}$, where g represents any number of power.

\subsection{The COPRAS-G approach}

The COPRAS-G technique uses the main ideas of complex proportional assessment methods with grey interval numbers, and works on a stepwise ranking and evaluation procedure of the alternatives in terms of their significance and utility degree. In this method, the parameters of the alternatives are determined with the grey relational grade. The grey systems theory (cf. Deng, 2005) focuses on the study of problems involving small samples, and deals with uncertain systems with partially known information. This technique has been used in many supply chain topics, such as supplier selection (Liou et al. 2016), website quality evaluation (Ecer 2014), machine tool selection (Nguyen et al. 2014) and performance evaluation of device (Bairagi et al. 2015). In this study, we apply the COPRAS-G method to calculate the utility degree and priority order of CLSP selection for disaster preparation, which consists of the following six steps.

Step 1 Identify the relevant criteria. Here we identify the criteria relevant for CLSP selection during the disaster preparedness stage.

Step 2 Construct the decision matrix, i.e., $\otimes X$. The matrix is determined by $\underline{X}_{j i}$, i.e., the smallest value (lower limit) and $\underline{X}_{j i}$, i.e., the biggest value (upper limit).

Step 3 Determine the importance weight of each criterion. This step determines the relative importance of each criterion $\left(\mathrm{q}_{i}\right)$ by using DANP.

Step 4 Calculate the weighted normalized decision matrix. In this step, we normalize $\otimes X$ in order to determine the importance weight of the selection criteria.

Step 5 Determine the relative significance of each alternative. In this step, we first calculate the sums $\mathrm{P}_{j}$ of the criterion values, i.e., whose larger values are more preferable. We then calculate the sums $\mathrm{R}_{j}$ of the criterion values, i.e., whose smaller values are more preferable.

Step 6 Calculate the utility degree of each alternative.

\section{Application}

Once the hybrid DANP-COPRAS-G method is built, the requisite data can be collected from executives of an HRO. If more than one person is responsible for the decision making 
process, then a DANP approach with group decision making can be carried out. While using this tool, the biased attitude of the decision maker can be alleviated by using additional group decision making techniques like (i) consensus, (ii) vote or compromise, and/or (iii) mean of the individual's judgments. For details, we refer the interested reader to Dyer and Forman (1992) and Jharkharia and Shankar (2007).

However, in MCDA situations, it may sometimes be difficult to arrive at consensus, which may lead to a compounding error amongst the factors due to expert bias. Therefore, instead of applying the commonly used DANP approach for solving such types of problems, this study recommends the use of a DANP based model with group decision making by taking the geometric mean value of individual judgments. This process can eliminate the bias of individual decision makers. In the reminder of this section, a case study is used to illustrate application of the proposed approach for selecting the most suitable CLSP in preparation for humanitarian relief operations.

\subsection{Background of the case organization}

The case study has been carried out at a leading HRO located in the southern part of India, who is an expert in humanitarian relief operations. The case HRO started its journey in the early 2000 and primarily working towards providing disaster relief and rehabilitation. The HRO has worked extensively with the victims of natural disasters like the 2001 Gujarat earthquake, the 2004 Tsunami of South India, and the 2015 Chennai floods. For example, immediately aftermath of earthquake in Gujarat, the HRO delivered over 40,000 food pockets and medical kits to the families of the victims. The case HRO has been involved in coordinating relief and rehabilitation efforts, and in facilitating information exchange among diverse players in the field of disaster relief.

Apart from the aforementioned disaster relief operations, the case HRO continues its work in the area of providing educational assistance to the children from underprivileged families in southern India state Tamilnadu. "Needs and Feeds" is one among the current initiatives of the HRO that facilitates donation in kind (used in good condition books, furniture, clothes, etc.) between donors and non-profit organizations. "StepOne" is another initiative of the HRO to facilitate job opportunities for persons with disability by facilitating a "One month Work Experience Opportunity." The case HRO also provides Social Entrepreneurship Fellowships to qualified social workers and entrepreneurs, who have passion to make a difference in a particular area of work, or wish to leverage their expertise in a particular area. The case HRO is joining hands with the Indian government for constructing toilets as a part "Swachh Bharat Abhiyan" initiative.

The case HRO relieves suffering caused by disasters through selecting, training and providing competent personnel for humanitarian assistance to people wherever needed. The staff, members and partners of the HRO are professional people committed to providing high quality training and expertise in disaster relief and rehabilitation. The case HRO believes that partnerships with individuals, other organizations and communities promote creative and fruitful initiatives. Therefore, the HRO has been working with some of the leading CLSPs for disaster relief operations during the 2004 Tsunami in Tamil Nadu and the 2015 Chennai floods. The problem is all about how the HRO is selecting its right CLSP partner during the preparedness stage of disaster relief. 
Table 2 The sum of influences given and received

\begin{tabular}{llllr}
\hline Criteria & $\mathrm{r}_{\mathrm{i}}$ & $\mathrm{s}_{\mathrm{i}}$ & $\mathrm{r}_{\mathrm{i}}+\mathrm{s}_{\mathrm{i}}$ & $\mathrm{r}_{\mathrm{i}}-\mathrm{s}_{\mathrm{i}}$ \\
\hline $\mathrm{C} 1$ & 1.703 & 1.959 & 3.662 & -0.256 \\
$\mathrm{C} 2$ & 2.203 & 2.012 & 4.215 & 0.191 \\
$\mathrm{C} 3$ & 1.618 & 1.794 & 3.412 & -0.176 \\
$\mathrm{C} 4$ & 1.661 & 1.641 & 3.302 & 0.020 \\
$\mathrm{C} 5$ & 2.378 & 1.904 & 4.282 & 0.474 \\
$\mathrm{C} 6$ & 1.416 & 1.669 & 3.085 & -0.253 \\
$\mathrm{C} 7$ & 1.376 & 1.161 & 2.537 & 0.215 \\
$\mathrm{C} 8$ & 0.676 & 0.990 & 1.666 & -0.314 \\
$\mathrm{C} 9$ & 1.096 & 1.178 & 2.274 & -0.082 \\
C10 & 1.391 & 1.210 & 2.601 & 0.181 \\
C11 & 1.105 & 1.446 & 2.551 & -0.341 \\
C12 & 1.139 & 1.147 & 2.286 & -0.008 \\
C13 & 0.803 & 0.730 & 1.533 & 0.073 \\
C14 & 1.298 & 1.022 & 2.320 & 0.276 \\
D1 & 5.000 & 3.000 & 8.000 & 2.000 \\
D2 & 4.500 & 5.000 & 9.500 & -0.500 \\
D3 & 3.500 & 5.000 & 8.500 & -1.500 \\
\hline
\end{tabular}

\subsection{Data collection approach and sample}

Initially, one of the authors of this paper has given a talk to the case HRO regarding the study motivation. To assess the interplay of the selected dimensions and criteria, we designed a questionnaire (see "Appendix"). We collected data from six different experts, including the south Indian head of the case HRO, one general manager, two managers who are in charge of logistics operations, and two training officers. All the six selected experts have rich experience about the working culture of the HRO in general and disaster relief operations in particular. These experts were asked to indicate the degree of influence pertaining to the factors on the following scale: 0 for "no influence," 1 for "minor influence," 2 for "somewhat influence," 3 for "high influence," and 4 for "extreme influence." We then asked the experts about both the minimum and maximum chances of selecting the CLSPs in terms of all the 14 criteria of the economic, technical and social dimensions.

\subsection{Measuring relationships by DEMATEL}

We adopt a DEMATEL decision-making structure and analyze three dimensions consisting of the 14 criteria, as well as the impact of the interrelationships among them. The average initial direct-relationship $14 \times 14$ matrix $A$ has been obtained by pairwise comparisons in terms of influences and directions between criteria. As matrix $A$ shows, the normalized directinfluence matrix $X$ was calculated. Then, the total influence $T_{c}$ and $T_{D}$ were derived, and by using Step 5, the NRM was constructed by the $\mathrm{r}_{\mathrm{i}}$ and $\mathrm{s}_{\mathrm{i}}$ in the total direct-influence matrix $T_{c}$ and $T_{D}$ (see Table 2 and Fig. 4). 


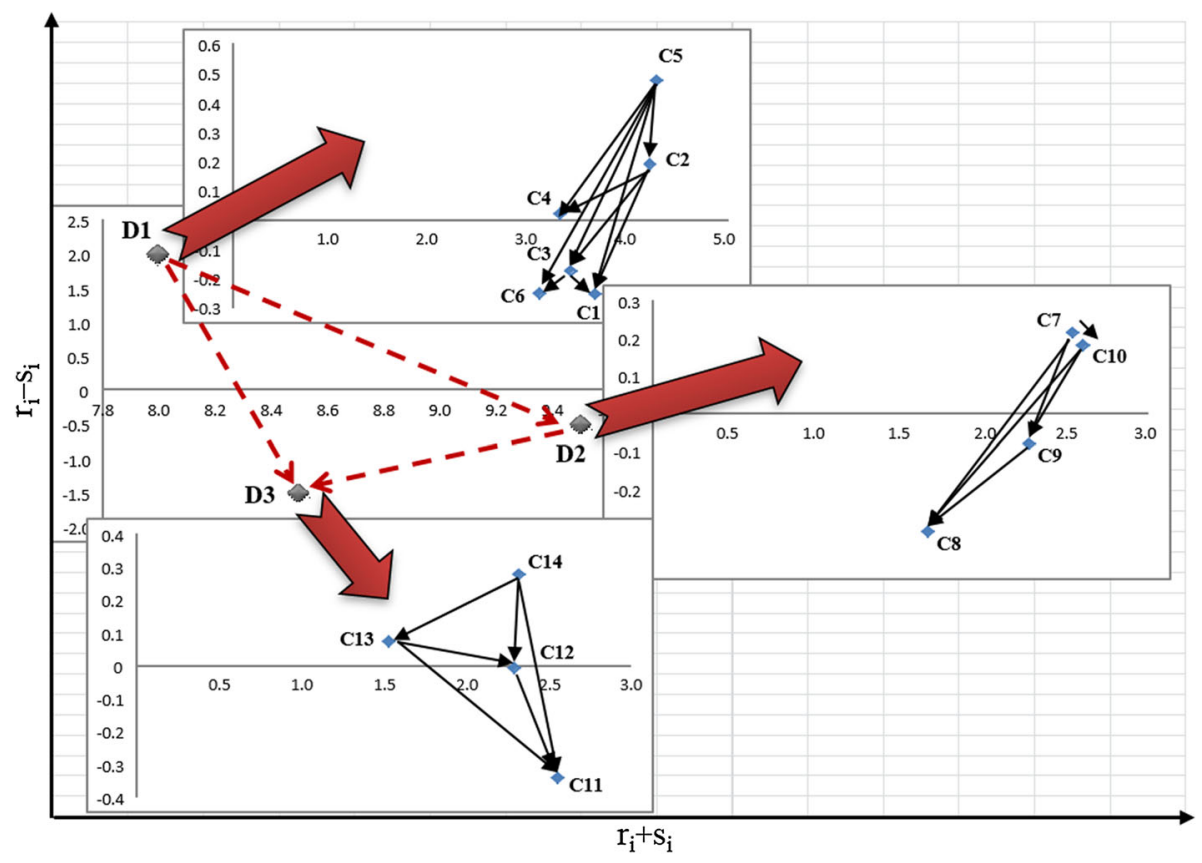

Fig. 4 Network relationship map

\subsection{Weighting by DANP technique}

Using the selected criteria, and combining the DEMATEL technique with the ANP method, we now solve the CLSP selection problem for disaster relief operations. ANP and DEMATEL has been combined (i.e., DANP) to obtain the normalized matrix $T_{c}$ by normalizing the totalinfluence matrix $T$. By calculating the limiting power of the weighted supermatrix, $\lim _{g \rightarrow \infty}$ $\left(W^{\alpha}\right)^{\mathrm{g}}$ has been applied until a steady-state condition is reached by a supermatrix convergence (see column 3 of Table 3 ).

\subsection{CLSP selection using COPRAS-G}

The criteria values shown in the rows of the stable DANP supermatrix after convergence were used as global weights in the COPRAS-G method for evaluating CLSPs for disaster relief. Next, the COPRAS-G decision making technique and the weights found from the DANP technique (see column 3 of Table 3) were used to evaluate the five shortlisted CLSPs. The general perceptions of the shortlisted CLSPs were established after initial discussions with all the six experts in the case HRO. The initial decision making matrix $\otimes X$ with all relevant information is presented in Table 3 . All our criteria are maximizing criteria with the exception of cost (i.e., minimizing) for CLSP evaluation for disaster relief. The values presented for the initial decision matrix are all interval values (see Table 3). By using Step 4, we normalized the initial decision matrix. We then constructed the weighted decision matrix (Table 4), and determined the relative significance of each alternative by calculating $\mathrm{P}_{j}, \mathrm{R}_{j}$, and $\mathrm{Q}_{j}$. Finally, we calculated the utility degree of each alternative CLSPs $\left(\mathrm{N}_{j}\right)$. 
Table 3 The initial decision matrix

\begin{tabular}{|c|c|c|c|c|c|c|c|c|}
\hline \multirow[t]{2}{*}{ Criterion } & & \multirow[t]{2}{*}{ Optimal } & \multirow[t]{2}{*}{ Weight } & \multicolumn{5}{|c|}{ Initial decision matrix } \\
\hline & & & & A1 & A2 & A3 & A4 & A5 \\
\hline$\otimes x_{1}$ & $\mathrm{C} 1$ & $\min$ & 0.043 & {$[70,80]$} & {$[90,95]$} & {$[85,95]$} & {$[65,80]$} & {$[45,60]$} \\
\hline$\otimes x_{2}$ & $\mathrm{C} 2$ & $\max$ & 0.045 & {$[60,80]$} & {$[70,80]$} & {$[40,50]$} & {$[55,70]$} & {$[75,90]$} \\
\hline$\otimes x_{3}$ & $\mathrm{C} 3$ & $\max$ & 0.037 & {$[80,90]$} & {$[50,70]$} & {$[60,75]$} & {$[65,70]$} & {$[55,70]$} \\
\hline$\otimes x_{4}$ & $\mathrm{C} 4$ & $\max$ & 0.035 & {$[50,70]$} & {$[40,50]$} & {$[70,85]$} & {$[70,80]$} & {$[70,90]$} \\
\hline$\otimes x_{5}$ & C5 & $\max$ & 0.041 & {$[50,60]$} & {$[80,85]$} & {$[60,80]$} & {$[60,70]$} & {$[70,80]$} \\
\hline$\otimes x_{6}$ & C6 & $\max$ & 0.035 & {$[70,85]$} & {$[60,80]$} & {$[75,90]$} & {$[80,90]$} & {$[50,60]$} \\
\hline$\otimes x_{7}$ & $\mathrm{C} 7$ & $\max$ & 0.098 & {$[55,70]$} & {$[50,60]$} & {$[70,80]$} & {$[70,80]$} & {$[45,55]$} \\
\hline$\otimes x_{8}$ & $\mathrm{C} 8$ & $\max$ & 0.082 & {$[70,80]$} & {$[60,75]$} & {$[75,85]$} & {$[70,85]$} & {$[50,60]$} \\
\hline$\otimes x_{9}$ & C9 & $\max$ & 0.100 & {$[65,80]$} & {$[60,80]$} & {$[65,70]$} & {$[55,60]$} & {$[70,80]$} \\
\hline$\otimes x_{10}$ & C10 & $\max$ & 0.104 & {$[70,90]$} & {$[40,55]$} & {$[65,85]$} & {$[50,70]$} & {$[80,90]$} \\
\hline$\otimes x_{11}$ & C11 & $\max$ & 0.129 & {$[80,85]$} & {$[60,80]$} & {$[85,95]$} & {$[45,60]$} & {$[65,75]$} \\
\hline$\otimes x_{12}$ & $\mathrm{C} 12$ & $\max$ & 0.099 & {$[70,80]$} & {$[60,75]$} & {$[80,85]$} & {$[70,75]$} & {$[55,65]$} \\
\hline$\otimes x_{13}$ & $\mathrm{C} 13$ & $\max$ & 0.060 & {$[75,90]$} & {$[55,70]$} & {$[60,70]$} & {$[50,65]$} & {$[75,80]$} \\
\hline$\otimes x_{14}$ & $\mathrm{C} 14$ & $\max$ & 0.088 & {$[75,90]$} & {$[55,70]$} & {$[70,80]$} & {$[50,60]$} & {$[80,90]$} \\
\hline
\end{tabular}

Table 4 The weighted decision matrix

\begin{tabular}{|c|c|c|c|c|c|}
\hline \multirow[t]{2}{*}{ Criterion } & \multicolumn{5}{|c|}{ Weighted decision matrix } \\
\hline & A1 & A2 & A3 & A4 & A5 \\
\hline$\underline{\left.\hat{x}_{1 n} ; \overline{\hat{x}}_{1 n}\right]}$ & {$[0.008,0.009]$} & {$[0.010,0.011]$} & {$[0.010,0.011]$} & {$[0.007,0.009]$} & {$[0.005,0.007]$} \\
\hline$\hat{x}_{2 n} ; \overline{\hat{x}}_{2 n}$ & {$[0.008,0.011]$} & {$[0.009,0.011]$} & {$[0.005,0.007]$} & {$[0.007,0.009]$} & {$[0.010,0.012]$} \\
\hline$\left.\underline{\hat{x}_{3 n}} ; \overline{\hat{x}}_{3 n}\right]$ & {$[0.009,0.010]$} & {$[0.005,0.008]$} & {$[0.006,0.008]$} & {$[0.007,0.008]$} & {$[0.006,0.008]$} \\
\hline$\left.\underline{\hat{x}_{4 n}} ; \overline{\hat{x}}_{4 n}\right]$ & {$[0.005,0.007]$} & {$[0.004,0.005]$} & {$[0.007,0.009]$} & {$[0.007,0.008]$} & {$[0.007,0.009]$} \\
\hline$\left[\hat{x}_{5 n} ; \overline{\hat{x}}_{5 n}\right]$ & {$[0.006,0.007]$} & {$[0.009,0.010]$} & {$[0.007,0.009]$} & {$[0.007,0.008]$} & {$[0.008,0.009]$} \\
\hline$\left[\hat{x}_{6 n} ; \overline{\hat{x}}_{6 n}\right]$ & {$[0.007,0.008]$} & {$[0.006,0.008]$} & {$[0.007,0.009]$} & {$[0.008,0.009]$} & {$[0.005,0.006]$} \\
\hline$\left.=\hat{x}_{7 n} ; \overline{\hat{x}}_{7 n}\right]$ & {$[0.017,0.022]$} & {$[0.015,0.019]$} & {$[0.022,0.025]$} & {$[0.022,0.025]$} & {$[0.014,0.017]$} \\
\hline$\left.=\hat{x}_{8 n} ; \overline{\hat{x}}_{8 n}\right]$ & {$[0.016,0.018]$} & {$[0.014,0.017]$} & {$[0.017,0.020]$} & {$[0.016,0.020]$} & {$[0.012,0.014]$} \\
\hline$\left.=\hat{x}_{9 n} ; \overline{\hat{x}}_{9 n}\right]$ & {$[0.019,0.023]$} & {$[0.018,0.023]$} & {$[0.019,0.020]$} & {$[0.016,0.018]$} & {$[0.020,0.023]$} \\
\hline 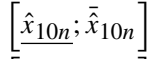 & {$[0.021,0.027]$} & {$[0.012,0.017]$} & {$[0.020,0.024]$} & {$[0.015,0.021]$} & {$[0.024,0.027]$} \\
\hline 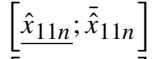 & {$[0.028,0.030]$} & {$[0.021,0.028]$} & {$[0.030,0.034]$} & {$[0.016,0.021]$} & {$[0.023,0.027]$} \\
\hline$\left.\hat{x}_{12 n} ; \overline{\hat{x}}_{12 n}\right]$ & {$[0.019,0.022]$} & {$[0.017,0.021]$} & {$[0.022,0.024]$} & {$[0.019,0.021]$} & {$[0.015,0.018]$} \\
\hline$\left.\hat{x}_{13 n} ; \overline{\hat{x}}_{13 n}\right]$ & {$[0.013,0.016]$} & {$[0.010,0.012]$} & {$[0.010,0.012]$} & {$[0.009,0.011]$} & {$[0.013,0.014]$} \\
\hline$\left[\hat{x}_{14 n} ; \overline{\hat{x}}_{14 n}\right]$ & {$[0.018,0.022]$} & {$[0.013,0.017]$} & {$[0.017,0.020]$} & {$[0.012,0.015]$} & {$[0.020,0.022]$} \\
\hline
\end{tabular}




\section{Results and discussion}

Based on the case study illustrated in the previous section, the approach proposed in this study provides several major findings. Insights from the results will be helpful for HROs who are in need of selecting the most appropriate CLSP for disaster preparation. Our findings are also insightful for CLSPs, given that they could achieve both humanitarian and commercial purposes by collaborating with HROs. In this section, we first present our study findings, and then discuss their implications for research and practice.

\subsection{Empirical results}

As shown in Fig. 4, the dimensions were found to be influencing each other. For example, D1 (economic) influences both D2 (technical) and D3 (social), whereas D2 influences D3, but not D1. That is, the economic criteria (D1) are the root cause, while technical (D2) and social (D3) criteria are the effects. This means that D1 is the most influential criteria in enhancing the involvement of CLSPs in disaster relief operations, followed by D2 and D3. The negative values of $\mathrm{r}_{\mathrm{i}}-\mathrm{s}_{\mathrm{i}}$ shown in Table 2 support this finding.

As the literature on humanitarian logistics suggests, D1 plays a crucial role in disaster relief operations (Van Wassenhove 2006; Kovács and Spens 2009). HROs might even modify their disaster relief strategies based on the selected CLSP's economic situation such as cost, quality and flexibility, albeit rarely. The literature also suggests that D2, influenced by D1, is crucial for disaster relief, often leading to increased D3 (Maon et al. 2009; Kovács et al. 2012; Alkhatib et al. 2015). This means that social-related factors, such as supporting community and crisis management, can be achieved by further efforts along with D1 and D2. Indeed, each dimension interacts with each other and acts as causes of or effects for CLSPs to participate in disaster relief operations.

As far as the economic dimension is concerned, we found that financial capability (C5) is the main cause factor. It appears that CLSP's financial capability has a positive impact on all the other economic criteria, as shown in the NRM (Fig. 4). Prior studies (e.g., Tomasini and Van Wassenhove 2009) argued that financial resources are one key element for disaster management. While providing evidence on this aspect, our results suggest that financially sound CLSPs are more likely to involve in disaster relief operations. The quality (C2) criterion was found to be another main cause factor, which enhances flexibility (C4), delivery (C3) and cost $(\mathrm{C} 1)$. In the literature, quality is regarded as a high level of importance given that its attributes directly affect customers (Jharkharia and Shankar 2007; Alkhatib et al. 2015). As our results reveal, this commercial-focused finding can also apply to the humanitarian context, suggesting that quality is key logistical abilities (Kovács et al. 2012) that cause CLSPs to engage in disaster relief operations.

It should be noted that cost $(\mathrm{C} 1)$ was found to be a relatively less influential factor for the involvement of CLSPs in disaster relief operations. On the one hand, this is contrary to our expectations considering that cost is the biggest obstacle to private-public partnership (Bealt et al. 2016). On the other, this might be expected given that CLSPs allocate free logistics capacity (e.g., transportation) to HROs as a CSR commitment (Vega and Roussat 2015). Our results suggest that for CLSPs, the cost factor is not a major consideration when deciding to engage in humanitarian relief.

Among the technical dimension, physical assets (C7) and innovation (C10) were found to influence all the other factors. This means that the greater these technical assets of the CLSP, the higher will be its forecasting ability (C9) and technology capability (C8). Real- 
Table 5 Utility degree evaluation of CLSPs for disaster preparation

\begin{tabular}{llllr}
\hline CLSP & $\mathrm{P}_{\mathrm{j}}$ & $\mathrm{R}_{\mathrm{j}}$ & $\mathrm{Q}_{\mathrm{j}}$ & $\mathrm{N}_{\mathrm{j}}(\%)$ \\
\hline $\mathrm{A} 1$ & 0.167 & 0.047 & 0.211 & 100.000 \\
$\mathrm{~A} 2$ & 0.139 & 0.046 & 0.183 & 87.141 \\
$\mathrm{~A} 3$ & 0.167 & 0.048 & 0.209 & 99.521 \\
$\mathrm{~A} 4$ & 0.143 & 0.043 & 0.191 & 90.471 \\
A5 & 0.157 & 0.041 & 0.206 & 98.091 \\
\hline
\end{tabular}

istic forecasting and technology capability are known to contribute to the effectiveness and efficiency of disaster relief operations (Balcik and Beamon 2008). Our findings suggest that physical assets and up-to-date innovation would help CLSPs to achieve both. Furthermore, in the social criteria, we found that the influence of stakeholders (C14) and grant and donations (C13) factors play a major role. These criteria seem to influence the other factors of the social dimension such as crisis management experience $(\mathrm{C} 12)$ and supporting community projects (C11). This result suggests that CLSPs may boost their social-related capabilities if they meet the stakeholders' needs and expectations.

However, according to the convergence supermatrix results derived from DANP (see "Weight" of Table 3), we found that $39 \%$ of the weightage is given to technical aspects (C7-10), 37\% to social aspects (C11-14), and the remaining 23\% to the economic aspects (C1-6) of the CLSP. As discussed above, the NRM (see Fig. 4) suggests that the economic dimension, especially financial capability (C5) and quality of services (C2) influences all the other 12 criteria. Surprisingly, yet, its supermatrix values after convergence were only found to be 0.041 and 0.045 respectively. This means that our HRO seems to prefer those CLSPs who are technically advanced and socially responsible. This is an interesting finding, given that economic-related factors are major causes for CLSPs to participate in disaster relief. We will discuss this result in more detail later.

Finally, as per the above-mentioned discussion and as shown in Table 5, A1 with a utility degree of $100 \%$ has been selected as the best CLSP, followed by A3 with a utility degree of $99.5 \%$ as the second best, and A5 with a utility degree of $98 \%$ as the third best. That is, A1 is having high relative significance $P_{j}$, followed by A3. In summary, A1>A3>A5>A4>A2. Thus, our case HRO seems to be interested in selecting CLSP A1 for disaster preparation, as they might be technically and socially satisfactory. Again, this is somewhat contrary to the results derived from DANP, suggesting that CLSPs are likely to involve in disaster relief operations when they are economically sound. This also warrants further discussion, which we present next.

\subsection{Implications for research}

Though the literature admits the need for a comprehensive methodology for designing indices for CLSP selection for disaster preparation, no conscious effort has been made to date in this direction. This lack of knowledge is echoed in a recent study by Baharmand et al. (2017) who argue that "research toward what criteria must be considered for selecting and cooperating with [C]LSPs in humanitarian contexts is missing" (p. 557). Against this background, this study takes a first step to identify the requisite criteria for CLSP selection from a STS perspective, observe the interdependency among the criteria, and then suggest a DANP and COPRAS-G based assessment framework. 
Our results showed that economic criteria are the most influential causes for CLSPs to involve in disaster relief. This study also revealed that technical and social criteria are the effects for the involvement of CLSPs in disaster relief, both of which are influenced by the economic dimension. Thus, decision making for CLSP involvement involves three interdependent sub-systems: economic, technical and social. This is in line with aspects of the STS discussed earlier, suggesting that each sub-system interacts to create organizational outcomes (Pasmore 1988; Griffith and Dougherty 2001; Kull et al. 2013). Our results suggest that all sub-systems must be considered holistically in collaboration with a CLSP for disaster relief. This gives a theoretical foundation for the evaluation of candidate CLSPs during the disaster preparedness stage, which has yet to emerge in the literature.

Relatedly, Kull et al. (2013) argued that before integration of suppliers into buyers, both parties are separate STSs, where typical boundary-spanning functions such as purchasing and marketing manage exchanges. After integration, however, the buying firms can enhance efficiency and effectiveness through integrating their technical systems with those of suppliers. By applying this aspect into the humanitarian context, this study suggests that even though HROs are limited in STS-related resources, they can enhance their relief operations by working with an appropriate CLSP. As will be discussed in detail later, technical-related systems are one crucial factor in the success of disaster relief (Balcik and Beamon 2008; Rodríguez-Espíndola et al. 2018). When a HRO selects and works with CLSPs, these systems are integrated (Kull et al. 2013), and such an integrated system would enhance disaster relief capacity, making the HRO more competitive. To our knowledge, this study is the first to adopt this thinking in the context of disaster relief, which is visually illustrated in Fig. 5.

Our review of the literature clearly shows that CLSPs play a significant role in accelerating disaster relief. Yet, most of the prior studies are limited to the role of CLSPs (e.g., Vega and Roussat 2015; Cozzolino et al. 2017). What is absent from the literature is an exploration of CLSP selection for disaster preparation. As noted before, we found that economic criteria are the major cause for CLSPs to participate in relief operations; but, those criteria are not actually major considerations for HROs in selecting CLSPs. Rather, our case HRO is more

$\mathrm{HRO}$

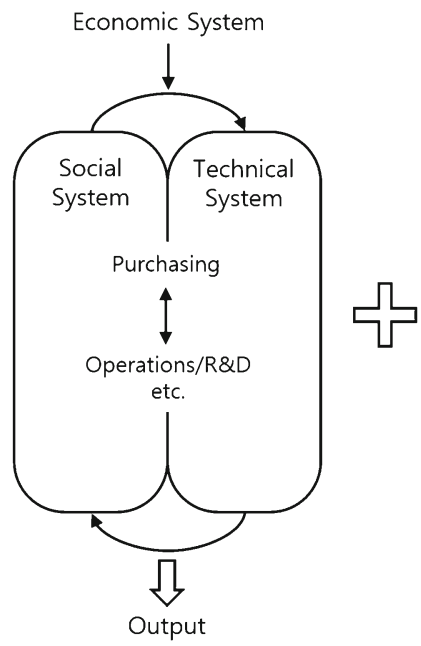

CLSP

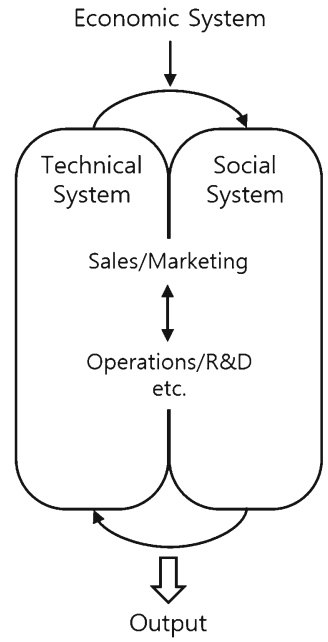

HRO based CLSP

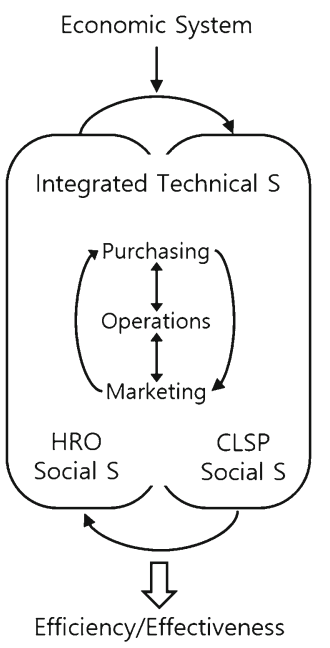

Fig. 5 STS perspective for the selection of a CLSP. Source: Own illustration, adapted from Kull et al. (2013) 
interested in CLSP's technical and social aspects of STS when deciding who to work with. Without additional efforts, being economically sound does not necessarily mean that the CLSPs are also technically and socially sound. In this regard, this study demonstrates how HROs can select the most appropriate CLSPs in preparation for disaster relief, thus extending the academic literature.

The contribution of this study also lies in our method applied to the context of humanitarian logistics. The current consensus seems to be that this field of research still remains immature in terms of analytic development (Özdamar and Ertem 2015; Griffith et al. 2017). Indeed, disaster relief research has not leveraged the DANP-based MCDA framework for the selection of CLSPs. The proposed hybrid model, comprising of DANP and COPRAS-G, provides a systemic analytical way for the selection of CLSPs for disaster preparation. In this study, we used DANP to determine the importance weight of the CLSP selection criteria for disaster relief, while applying COPRAS-G to select the most suitable CLSP for the case HRO. As discussed at the beginning of this paper, such a hybrid model complements the commonly used techniques for selection matters such as AHP and ANP. In this sense, our approach can add breadth to the depth of our understanding of the modeling techniques applied in this field of humanitarian logistics research.

\subsection{Implications for practice}

In this study, we found that economically sound CLSPs, especially with finical capability and quality of service, are likely to participate in disaster relief. This indicates that our case CLSPs might involve in the relief as a CSR commitment (i.e., "member" role), or as a source for ad hoc contracts (i.e., "tool” role) (Vega and Roussat 2015). In other words, CLSPs simply share their available resources (e.g., transportation) with HROs, or they are just interested in acting as operators on a contract basis. In this reactive approach, however, relief operations are more short-term based, with limited logistics resources (Tomasini and Van Wassenhove 2009; Wang et al. 2016). The efficacy of this approach might thus be limited, causing HROs to still face challenges in accelerating disaster response.

This aspect seems to be reflected in our COPRAS-G results. As noted before, the convergence supermatrix results show that our case HRO prefers working with those CLSPs who are technically advanced and socially responsible. This suggests that for HROs, the best selection of CLSPs in preparation for disaster relief depends on the criteria associated with technical (e.g., physical assets and innovation) and social (e.g., stakeholders and grants/donations) dimensions, not with economic factors such as financial capability. In other words, HROs can advance their relief operations by collaborating with those CLSPs who could provide logistical support with high technical skills and ample experience with relief operations. In our view, these kinds of CLSPs act as "actors" or "partners" (Vega and Roussat 2015), who "work diligently to propose their logistics services overlapping philanthropic and commercial intentions" in disaster relief (Cozzolino et al. 2017, p. 286). This proactive approach is more long-term based (Tomasini and Van Wassenhove 2009; Wang et al. 2016), which may deem relief tasks as a core part of business activity.

The relative importance of CLSP's technical and social abilities in disaster relief can be seen in real cases. For example, despite financial constraints, IFRC (International Federation of Red Cross and Red Crescent Societies) have made an effective disaster relief mission by working with highly technical and experienced CLSPs (Van Wassenhove 2006). Looking at empirical evidence, some studies have also supported this observation, albeit implicitly. Using a survey of 85 experts in disaster response, Bealt et al. (2016) found that the degree of 
involvement of CLSPs is one of the major barriers to achieving effective relief operations. This is consistent with the findings of Vega and Roussat (2015), showing that the majority of CLSPs restrict their relief involvement to CSR commitments. Rodríguez-Espíndola et al. (2018) also found that the lack of collaboration with CLSPs may lead to ineffective disaster relief, even though HROs possess sufficient resources.

Building on STS theory and its relevant criteria, we revealed that CLSPs with high technical abilities and social betterment are more likely to enhance HROs' humanitarian relief operations. This finding is thus a wake-up call for those HROs who only consider economic factors, such as financial capability, when it comes to selecting and working with CLSPs. In fact, HROs already compete among themselves to get a better position in the field (Van Wassenhove 2006; Kovács and Spens 2009). Our study results provide them, in particular low-performing HROs, with useful guidance on what they should do next if they seek an outstanding positioning in disaster relief operations.

We now turn to discuss implications of our findings for CLSPs. When CLSPs participate in disaster relief as CSR commitments, they have to spend their own budget as HROs, who has limited funding resources, cannot cover everything (Balcik and Beamon 2008; Wang et al. 2016). However, given the social norm for businesses to engage in social responsibility, this is a worthwhile investment for the CLSPs. This is because there is an obvious benefit of this type of involvement: improving public image. Consider TNT as an example, whose relief operations were beneficial not only to the communities, but were also adding value for them (Van Wassenhove 2006). In this regard, CLSPs might involve in relief operations mainly for a strategic purpose of mollifying public concerns.

However, there are drawbacks to this strategy. One might be associated with the question of how can CLSPs align their needs with those of relevant stakeholders (Swansson and Smith 2013). In India, the Ministry of Corporate Affairs has notified Section 135 and Schedule VII of the Companies Act, which is related to CSR. Effective from April 1, 2013, this norm applies to companies with at least Rs 5 crore net profit or Rs 1,000 crore turnovers or Rs 500 crore net worth. Indeed, companies are forced to spend $2 \%$ of their three-year average annual net profit on CSR activities. This coercive measure might trigger CLSPs to engage in CSR activities like humanitarian tasks. Yet in a sense, this might also lead the CLSPs to invest in CSR only to the extent required by the law (i.e., 2\%). The latter point is often subject to skepticism about the CSR activities, making CLSPs difficult to convince relevant stakeholders. This skepticism may then lead to inconsistent information about the CLSPs' CSR activities and therefore "corporate hypocrisy" (Wagner et al. 2009).

In this study, we argue that for their activities to be truly socially responsible, CLSPs' relief operations should be more than just a "symbolic or political" (Ballesteros et al. 2017) investment. That is, it must go beyond tax savings, profit, and the legal requirement (Swansson and Smith 2013). That should be based on a relationship with relevant stakeholders, which is built up over years and/or decades (Kim and Lee 2012). This effort would help CLSPs to craft more robust CSR strategies, involving disaster relief operations. Such a competence may also give them more chances for collaborating with HROs, and therefore achieved stakeholder needs. Indeed, CLSPs can better align their strategy with the needs of stakeholders by making a genuine stride in CSR. 


\section{Conclusion}

Today, the world faces the challenges posed by disasters like earthquakes, a catastrophic event that overwhelms local capacity. To better cope with this, many HROs are coming up with the idea of collaborating with the private sector (Stewart et al. 2009; Gabler et al. 2017), especially with CLSPs (Van Wassenhove 2006; Swansson and Smith 2013; Vega and Roussat 2015). In this context, selection for a right CLSP in the disaster preparedness stage constitutes an important MCDM problem for effective humanitarian operations. Despite the practical importance, yet, there is a dearth of research into this aspect. This lack of scholarly attention is more apparent when compared with research on the selection of logistics service provider for commercial activities (e.g., Jharkharia and Shankar 2007). This study contributes to the extant literature by examining how HROs can select the most appropriate CLSP in preparation for disaster relief operations.

The proposed methodology has limitations though. First of all, DANP relies heavily on expert opinions, which may be biased by the subjectivity and transitivity associated with the decision maker. Therefore, there is a need for a better aggregation methodology-for example, the same problem can be analyzed by fuzzy DANP based COPRAS-G, so that the vagueness of the opinion of the decision maker can be taken care of. On top of that, a userfriendly interface needs to be developed to simplify the DANP and COPRAS-G calculations so as to use the proposed approach in real-life problems more easily. The outcome of the model presented is purely dependent on the inputs provided by the experts of the case HRO. Thus, further refinement of the model can be done by additional field studies or by conducting surveys with other organizations.

Open Access This article is distributed under the terms of the Creative Commons Attribution 4.0 International License (http://creativecommons.org/licenses/by/4.0/), which permits unrestricted use, distribution, and reproduction in any medium, provided you give appropriate credit to the original author(s) and the source, provide a link to the Creative Commons license, and indicate if changes were made.

\section{Appendix}

See Tables 6 and 7.

Table 6 An excerpt of DANP questionnaire for economic factors

\begin{tabular}{lcccccc}
\hline Criterion & $(\mathrm{C} 1)$ & $(\mathrm{C} 2)$ & (C3) & (C4) & (C5) & (C6) \\
\hline Cost (C1) & & 4 & & & \\
Quality (C2) & 1 & & & & \\
Delivery (C3) & & & & & \\
Flexibility (C4) & & & & & \\
Financial capability (C5) & & & & \\
Relationship (C6) & & & & & \\
\hline
\end{tabular}

Examples: If the degree of influence of $\mathrm{C} 1$ to $\mathrm{C} 2$ is extreme, then fill 4 into the cross blank of $\mathrm{C} 1$ and $\mathrm{C} 2$. If the degree of influence of $\mathrm{C} 2$ to $\mathrm{C} 1$ is minor, then fill 1 into the cross blank of $\mathrm{C} 2$ and $\mathrm{C} 1$ 
Table 7 COPRAS-G questionnaire for initial decision

\begin{tabular}{|c|c|c|c|c|c|c|c|c|c|c|}
\hline \multirow[t]{2}{*}{ Criterion } & \multicolumn{2}{|c|}{ CLSP1 } & \multicolumn{2}{|c|}{ CLSP2 } & \multicolumn{2}{|c|}{ CLSP3 } & \multicolumn{2}{|l|}{ CLSP4 } & \multicolumn{2}{|c|}{ CLSP5 } \\
\hline & $\operatorname{Min} \%$ & Max\% & $\operatorname{Min} \%$ & $\operatorname{Max} \%$ & $\operatorname{Min} \%$ & $\operatorname{Max} \%$ & Min \% & Max\% & Min \% & $\operatorname{Max} \%$ \\
\hline \multicolumn{11}{|l|}{ Cost } \\
\hline \multicolumn{11}{|l|}{ Quality } \\
\hline \multicolumn{11}{|l|}{ Delivery } \\
\hline \multicolumn{11}{|l|}{ Flexibility } \\
\hline \multicolumn{11}{|l|}{ Financial capability } \\
\hline \multicolumn{11}{|l|}{ Relationship } \\
\hline \multicolumn{11}{|l|}{$\begin{array}{l}\text { Physical facilities } \\
\text { and assets }\end{array}$} \\
\hline \multicolumn{11}{|l|}{$\begin{array}{l}\text { Technology } \\
\text { capability }\end{array}$} \\
\hline \multicolumn{11}{|l|}{ Forecasting ability } \\
\hline \multicolumn{11}{|l|}{ Innovation } \\
\hline \multicolumn{11}{|l|}{$\begin{array}{l}\text { Supporting } \\
\text { community } \\
\text { projects }\end{array}$} \\
\hline \multicolumn{11}{|l|}{$\begin{array}{l}\text { Crisis management } \\
\text { experience }\end{array}$} \\
\hline \multicolumn{11}{|l|}{ Grants and donations } \\
\hline $\begin{array}{l}\text { Influence of } \\
\text { stakeholders }\end{array}$ & & & & & & & & & & \\
\hline
\end{tabular}

Please mention the minimum and maximum chances of selecting the CLSPs in terms of all the criteria

\section{References}

Abidi, H., De Leeuw, S., \& Klumpp, M. (2015). The value of fourth-party logistics services in the humanitarian supply chain. Journal of Humanitarian Logistics and Supply Chain Management, 5(1), 35-60.

Alkhatib, S. F., Darlington, R., \& Nguyen, T. T. (2015). Logistics service providers (LSPs) evaluation and selection: Literature review and framework development. Strategic Outsourcing: An International Journal, $8(1), 102-134$.

Baharmand, H., Comes, T., \& Lauras, M. (2017). Managing in-country transportation risks in humanitarian supply chains by logistics service providers: Insights from the 2015 Nepal earthquake. International Journal of Disaster Risk Reduction, 24, 549-559.

Bai, C., \& Sarkis, J. (2010). Integrating sustainability into supplier selection with grey system and rough set methodologies. International Journal of Production Economics, 124(1), 252-264.

Bairagi, B., Dey, B., Sarkar, B., \& Sanyal, S. K. (2015). A De Novo multi-approaches multi-criteria decision making technique with an application in performance evaluation of material handling device. Computers \& Industrial Engineering, 87, 267-282.

Balcik, B., \& Ak, D. (2014). Supplier selection for framework agreements in humanitarian relief. Production and Operations Management, 23(6), 1028-1041.

Balcik, B., \& Beamon, B. M. (2008). Facility location in humanitarian relief. International Journal of Logistics: Research and Applications, 11(2), 101-121.

Ballesteros, L., Useem, M., \& Wry, T. (2017). Masters of disasters? An empirical analysis of how societies benefit from corporate disaster aid. Academy of Management Journal, 60(5), 1682-1708.

Bealt, J., Camilo, J., Barrera, F., \& Mansouri, S. A. (2016). Collaborative relationships between logistics service providers and humanitarian organizations during disaster relief operations. Journal of Humanitarian Logistics and Supply Chain Management, 6(2), 118-144.

Burkart, C., Nolz, P. C., \& Gutjahr, W. J. (2017). Modelling beneficiaries' choice in disaster relief logistics. Annals of Operations Research, 256(1), 41-61. 
Chemweno, P., Pintelon, L., Horenbeek, A. V., \& Muchiri, P. (2015). Development of a risk assessment selection methodology for asset maintenance decision making: An analytic network process (ANP) approach. International Journal of Production Economics, 170, 663-676.

Closs, D. J., Jacobs, M. A., Swink, M., \& Webb, G. S. (2008). Toward a theory of competencies for the management of product complexity: Six case studies. Journal of Operations Management, 26(5), 590-610.

Cozzolino, A., Wankowicz, E., \& Massaroni, E. (2017). Logistics service providers' engagement in disaster relief initiatives: An explorative analysis. International Journal of Quality and Service Sciences, 9(3/4), 269-291.

Deng, J. (2005). The primary methods of grey system theory. Wuhan: Huazhong University of Science and Technology Press.

Dyer, R. F., \& Forman, E. H. (1992). Group decision support with the analytic hierarchy process. Decision Support Systems, 18(2), 163-187.

Ecer, F. (2014). A hybrid banking websites quality evaluation model using AHP and COPRAS-G: A Turkey case. Technological and Economic Development of Economy, 20(4), 758-782.

Gabler, C. B., Rochey, R. G., Jr., \& Stewart, G. T. (2017). Disaster resilience through public-private short-term collaboration. Journal of Business Logistics, 38(2), 130-144.

Griffith, D. A., Boehmke, B., Bradley, R. V., Hazen, B. T., \& Johnson, A. W. (2017). Embedded analytics: Improving decision support for humanitarian logistics operations. Annals of Operations Research, 9, 99. https://doi.org/10.1007/s10479-017-2607-z.

Griffith, T. L., \& Dougherty, D. J. (2001). Beyond socio-technical systems: Introduction to the special issue. Journal of Engineering and Technology Management, 18(3-4), 207-218.

Guha-Sapir, D., Hoyois, P., \& Below, R. (2015). Annual disaster statistical review 2015: The numbers and trends. Center for Research on the Epidemiology of Disasters (CRED).

Hadid, W., Mansouri, S. A., \& Gallear, D. (2016). Is lean service promising? A socio-technical perspective. International Journal of Operations \& Production Management, 36(6), 618-642.

Holguín-Veras, J., Miguel, J., Van Wassenhove, L. N., Pérez, N., \& Wachtendorf, T. (2012). On the unique features of post-disaster humanitarian logistics. Journal of Operations Management, 30(7-8), 496-506.

Horwitz, S. (2008). Wal-Mart to the rescue: Private enterprise's response to Hurricane Katrina. The Independent Review, 13(4), 511-528.

Jahre, M., Jensen, L. M., \& Listou, T. (2009). Theory development in humanitarian logistics: A framework and three cases. Management Research News, 32(11), 1008-1023.

Jharkharia, S., \& Shankar, R. (2007). Selection of logistics service provider: An analytic network process (ANP) approach. Omega, 35(3), 274-289.

Kabra, G., \& Ramesh, A. (2015). Analyzing drivers and barriers of coordination in humanitarian supply chain management under fuzzy environment. Benchmarking: An International Journal, 22(4), 559-587.

Keskin, G. A. (2015). Using integrated fuzzy DEMATEL and fuzzy C: Means algorithm for supplier evaluation and selection. International Journal of Production Research, 53(12), 3586-3602.

Kılcı, F., Kara, B. Y., \& Bozkaya, B. (2015). Locating temporary shelter areas after an earthquake: A case for Turkey. European Journal of Operational Research, 243(1), 323-332.

Kim, S. T., \& Lee, S. Y. (2012). Stakeholder pressure and the adoption of environmental logistics practices: Is eco-oriented culture a missing link? International Journal of Logistics Management, 23(2), 238-258.

Kovács, G., \& Spens, K. M. (2007). Humanitarian logistics in disaster relief operations. International Journal of Physical Distribution \& Logistics Management, 37(2), 99-114.

Kovács, G., \& Spens, K. M. (2009). Identifying challenges in humanitarian logistics. International Journal of Physical Distribution \& Logistics Management, 39(6), 506-528.

Kovács, G., Tatham, P., \& Larson, P. D. (2012). What skills are needed to be a humanitarian logistician? Journal of Business Logistics, 33(3), 245-258.

Kull, T. J., Ellis, S. C., \& Narasimhan, R. (2013). Reducing behavioural constraints to supplier integration: A socio-technical systems perspective. Journal of Supply Chain Management, 49(1), 64-86.

Liou, J. J., Tamošaitienė, J., Zavadskas, E. K., \& Tzeng, G. H. (2016). New hybrid COPRAS-G MADM model for improving and selecting suppliers in green supply chain management. International Journal of Production Research, 54(1), 114-134.

Maon, F., Lindgreen, A., \& Vanhamme, J. (2009). Developing supply chains in disaster relief operations through cross-sector socially oriented collaborations: A theoretical model. Supply Chain Management: An International Journal, 14(2), 149-164.

Nguyen, H. T., Dawal, S. Z. M., Nukman, Y., \& Aoyama, H. (2014). A hybrid approach for fuzzy multiattribute decision making in machine tool selection with consideration of the interactions of attributes. Expert Systems with Applications, 41(6), 3078-3090.

Özdamar, L., \& Ertem, M. A. (2015). Models, solutions and enabling technologies in humanitarian logistics. European Journal of Operational Research, 244(1), 55-65. 
Pasmore, W. (1988). Designing effective organizations: The socio-technical systems perspective. New York: Wiley.

Ramkumar, M., \& Jenamani, M. (2015). Sustainability in supply chain through E-procurement—An assessment framework based on DANP and Liberatore score. IEEE Systems Journal, 9(4), 1554-1564.

Ramkumar, M., Schoenherr, T., \& Jenamani, M. (2016). Risk assessment of outsourcing e-procurement services: integrating SWOT analysis with a modified ANP-based fuzzy inference system. Production Planning \& Control, 27(14), 1171-1190.

Rodríguez-Espíndola, O., Albores, P., \& Brewster, C. (2018). Disaster preparedness in humanitarian logistics: A collaborative approach for resource management in floods. European Journal of Operational Research, 264(3), 978-993.

Sharma, B., Ramkumar, M., Subramanian, N., \& Malhotra, B. (2017). Dynamic temporary blood facility location-allocation during and post-disaster periods. Annals of Operations Research. https://doi.org/10. 1007/s10479-017-2680-3.

Stewart, G. T., Kolluru, R., \& Smith, M. (2009). Leveraging public-private partnerships to improve community resilience in times of disaster. International Journal of Physical Distribution \& Logistics Management, 39(5), 343-364.

Subramanian, N., \& Ramanathan, R. (2012). A review of applicants of Analytic Hierarchy Process in operations management. International Journal of Production Economics, 138(2), 215-241.

Swansson, R. D., \& Smith, R. J. (2013). A path to a public-private partnership: Commercial logistics concepts applied to disaster response. Journal of Business Logistics, 34(4), 335-346.

Tadić, S., Zečević, S., \& Krstić, M. (2014). A novel hybrid MCDM model based on fuzzy DEMATEL, fuzzy ANP and fuzzy VIKOR for city logistics concept selection. Expert Systems with Applications, 41(18), 8112-8128.

Tomasini, R. M., \& Van Wassenhove, L. N. (2009). From preparedness to partnerships: Case study research on humanitarian logistics. International Transactions in Operational Research, 16(5), 549-559.

Trivedi, A., \& Singh, A. (2017). A hybrid multi-objective decision model for emergency shelter location-relocation projects using fuzzy analytic hierarchy process and goal programming approach. International Journal of Project Management, 35(5), 827-840.

Tzeng, G. H., \& Huang, C. Y. (2014). Combined DEMATEL technique with hybrid MCDM methods for creating the aspired intelligent global manufacturing \& logistics systems. Annals of Operations Research, 197(1), 159-190.

Van Wassenhove, L. N. (2006). Humanitarian aid logistics: Supply chain management in high gear. Journal of the Operational Research Society, 57(5), 475-489.

Vega, D., \& Roussat, C. (2015). Humanitarian logistics: The role of logistics service providers. International Journal of Physical Distribution \& Logistics Management, 45(4), 352-375.

Wagner, T., Lutz, R. J., \& Weitz, B. A. (2009). Corporate hypocrisy: Overcoming the threat of inconsistent corporate social responsibility perceptions. Journal of Marketing, 73(6), 77-91.

Wang, X., Wu, Y., Liang, L., \& Huang, Z. (2016). Service outsourcing and disaster response methods in a relief supply chain. Annals of Operations Research, 240(2), 471-487.

Publisher's Note Springer Nature remains neutral with regard to jurisdictional claims in published maps and institutional affiliations. 